\section{What do we do about the problem of overweight and obesity in the Americas?}

\author{
Surujpal Teelucksingh ${ }^{1}$
}

Two papers in this issue of the Revista Panamericana de Salud Pública/Pan American Journal of Public Health address the growing epidemic of obesity in the Region of the Americas, focusing on the English-speaking Caribbean (1) and on Ecuador (2). Another article earlier this year in the Revista/Journal reported on the "alarming" prevalence of obesity and overweight in Costa Rican schoolchildren and said that that country's future health burden attributable to excess weight gain "is likely to be huge" (3).

Within the last two decades the prevalence of obesity in the developed world has moved from single digits to near $20 \%$ (4). Even more alarming is that within the same time frame the prevalence of overweight in the developing world has exceeded that in the developed countries, with, for example, rates of up to $30 \%$ in adult females being reported in the Caribbean $(5,6)$. This disproportionate increase in the developing world is expected to accelerate even further since individuals, health care providers, and planners have been slow to either recognize or react to the problem.

Individuals have been blinded by cultural factors that interpret obesity as desirable and as a sign of wealth and economic success. Many planners lack sufficient financial resources and personnel—and, most importantly, adequate local data with which to influence public policy decisions. Clinicians have been coached in the model of acute care, and they operate in environments ill suited to handling chronic, lifestyle-related diseases.

The article on Ecuador (2) in this issue reports that among the secondary schoolgirls surveyed in a semiurban area near Quito, the average prevalence of obesity is somewhat lower than the average for the Region of the Americas. That finding, however, should not make us feel either complacent or comfortable. The epidemic of obesity has already entered the childhood and adolescent age groups, with rates of overweight of up to $10 \%$ having been reported in the developing countries of the Americas, including Trinidad and Tobago, according to one recent article (7). Obesity among children and youths will put those individuals at risk for health complications in adulthood, when their economic productivity should be the greatest. Rather than contributing the most possible to their countries' prosperity, these persons will become consumers of already-scarce resources.

Unfortunately, obesity does not exist in isolation but is frequently associated with other comorbid factors (e.g., hypertension, type 2 diabetes, and dyslipidemia), which together lead to a high susceptibility to cardiovascular disease and premature death. While obesity is a risk factor for preventable cardiovascular disease in its own right, obesity is also frequently associated with an increased prevalence of cancers, obstructive sleep apnea, osteoarthrosis, accidental injury, and depression.

In his article on the English-speaking Caribbean (1), Fraser highlights the scale and scope of the problem in that part of the Americas, and he then goes on to enumerate a priority list of actions that could stem the rising tide of the obesity epidemic. His prescription is for multifaceted interventions. Clearly, the first and foremost challenge will be to overcome the cultural biases that favor corpulence. 
Slaying this monster will then require concerted and coordinated effort among planners, public health educators, teachers, and community leaders. Treatment needs to shift from expensive, institution-based interventions to community-based ones that have a strong behavioral component. Anyone ready to offer a workable model?

\section{REFERENCES}

1. Fraser H. Obesity: diagnosis and prescription for action in the English-speaking Caribbean. Rev Panam Salud Publica 2003;13(5):336-340.

2. Castro Burbano J, Fornasini M, Acosta M. Prevalencia y factores de riesgo de sobrepeso en colegialas de 12 a 19 años en una región semiurbana del Ecuador. Rev Panam Salud Publica 2003;13(5):277-284

3. Núñez-Rivas HP, Monge-Rojas R, León H, Roselló M. Prevalence of overweight and obesity among Costa Rican elementary school children. Rev Panam Salud Publica 2003;13(1):24-32.

4. Brynes AE, Frost GS, Goldstone AP. Why do adults become obese? Postgraduate Doctor Caribbean 2002:18(5) Special Supplement:1-10.

5. Foster C, Rotimi C, Fraser H, Sundarum C, Liao Y, Gibson E, et al. Hypertension, diabetes and obesity in Barbados: findings from a recent population-based survey. Ethn Dis 1993;3(4):404-412.

6. Wilks R, Bennett F, Forrester T, McFarlane-Anderson N. Chronic diseases: the new epidemic. West Indian Med J 1998;47 Suppl 4:40-44.

7. Gulliford MC, Mahabir D, Rocke B, Chinn S, Rona R. Overweight, obesity and skinfold thickness of children of African or Indian descent in Trinidad and Tobago. Int J Epidemiol 2001;30(5):989-998. 